\title{
An update on cervical cancer screening in Vanuatu
}

Emma R Allanson, Houston, USA; Vera Velanova, Brisbane, Australia; lan H Frazer, Woolloongabba, Australia; Margaret McAdam, Brisbane, Australia, Woolloongabba, Australia and Cervical Cancer Foundation (Logistics Support), Vanuatu Ministry of Health, Sullivan Nicolaides Pathology, Frazer Family Foundation

The Republic of Vanuatu is a lower middle income country in the Pacific Ocean comprising 83 volcanic islands with a population of around $300000 .{ }^{1}$ The incidence of cervical cancer in Vanuatu is estimated to be around 100 per 100000 women, ${ }^{2}$ with an average age at diagnosis of 44 years and an average age of death from the disease of 45 years. $^{3}$

Initial pilot studies for cervical cancer screening began in Vanuatu in 2006, ${ }^{2}$ and a formalized screening program has been in place since 2008, executed by a committed and enthusiastic group of local nurses and doctors who are supported by a locally trained cytopathologist alongside volunteer support from Australian pathologists (from Sullivan Nicolaides laboratories). Since 2015, cervical screening has largely taken the form of cytological screening and/ or human papillomavirus (HPV) testing, with concurrent dedicated data collection related to the program. Here we present an update.

From January 2015 to June 2019, 13 $933(19.9 \%)$ of the 70063 eligible women (aged 20-65 years) in Vanuatu underwent screening, including 30\% (9133/30 424) of eligible 30-50-year-old women. HPV testing (CareHPV, Qiagen) has been possible thanks to the testing kits donated by the Frazer Family Foundation. Of the 8593 women screened for HPV, 857 (10\%) were screen positive. In addition, 10897 Pap smears were performed, with a high grade as a result in $260(2.39 \%)$ patients. Just over half of the women with highgrade Pap smears $(133 / 260,51.1 \%)$ also had an HPV test, of which 101 (75.9\%) were positive. Treatment (large loop excision of the transformation zone) of highgrade Pap smear results has increased from $40.5 \%$ in 2015 to $61.9 \%$ in 2018 . In the screened women, 97 cancers were detected, with six $(0.2 \%)$ of 2894 women aged $<30$ years, $55(0.5 \%)$ of 10135 women aged $30-50$ years, and $36(1.6 \%)$ of 2181 women aged $>50$. Anecdotally, there are many more undiagnosed and

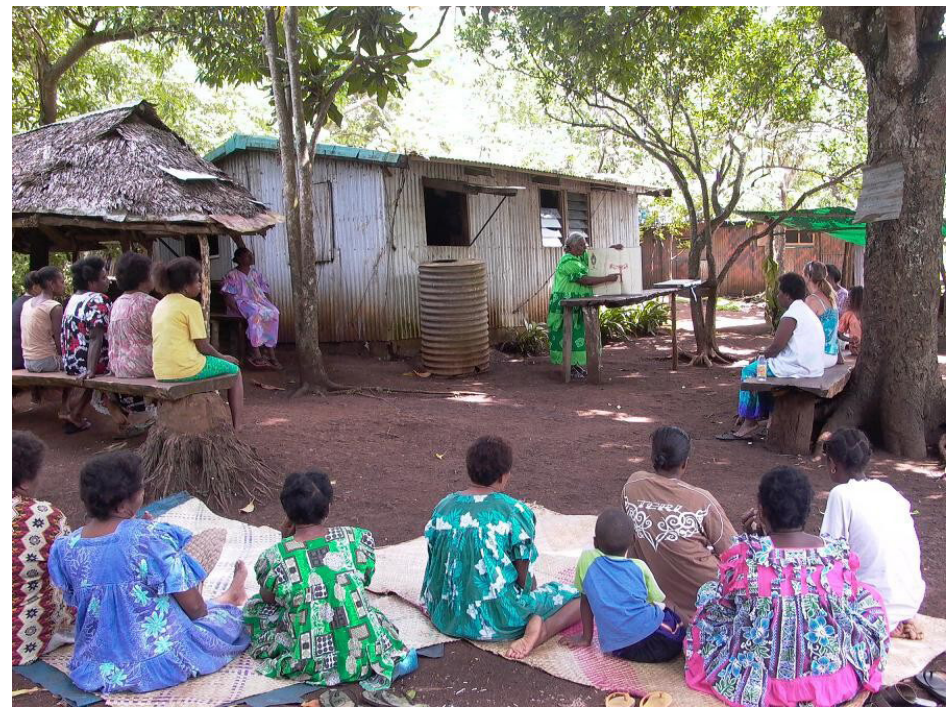

Figure 1 Cervical cancer education in the villages.

symptomatic cancers, particularly on the outer more remote islands.

One of the issues in Vanuatu is reaching women who live on the remote islands, and this is borne out in the screening data, with the rates of eligible women being screened varying across islands from $<1 \%$ to nearly $90 \%$ (Figure 1). Other ongoing challenges

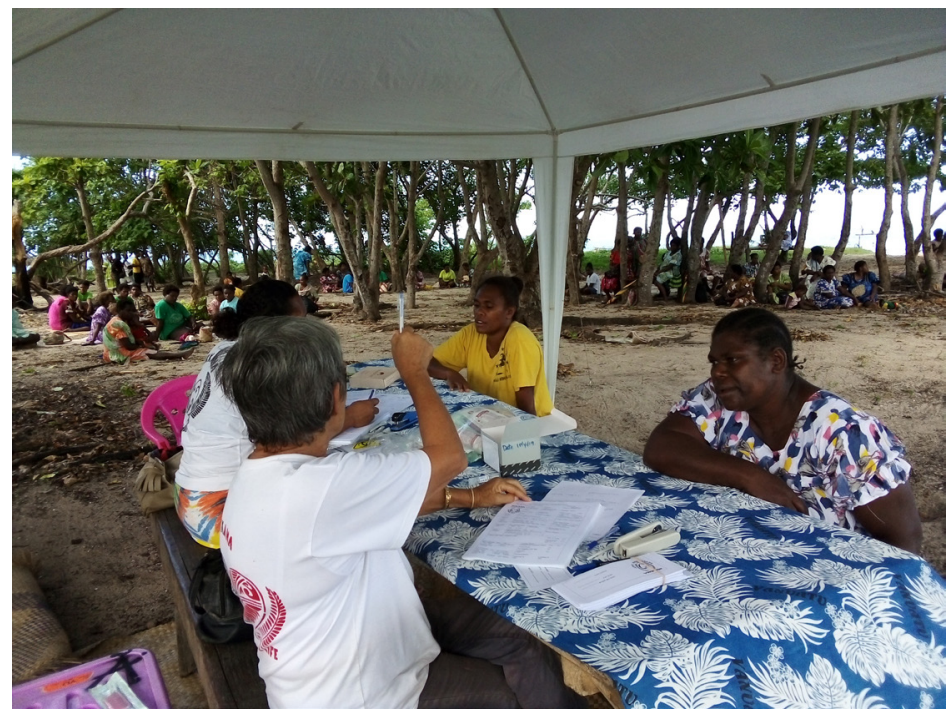

Figure 2 IKKANA-led cervical cancer screening outreach program at Hokai on the South Malekula island in May 2020.

in cervical screening include patients having to travel a long distance to seek screening and treatment, the use of alternative medicines, lack of health education, and financial constraints including the expense of transporting women to an island where excisional treatment is available. One great innovation to address this 


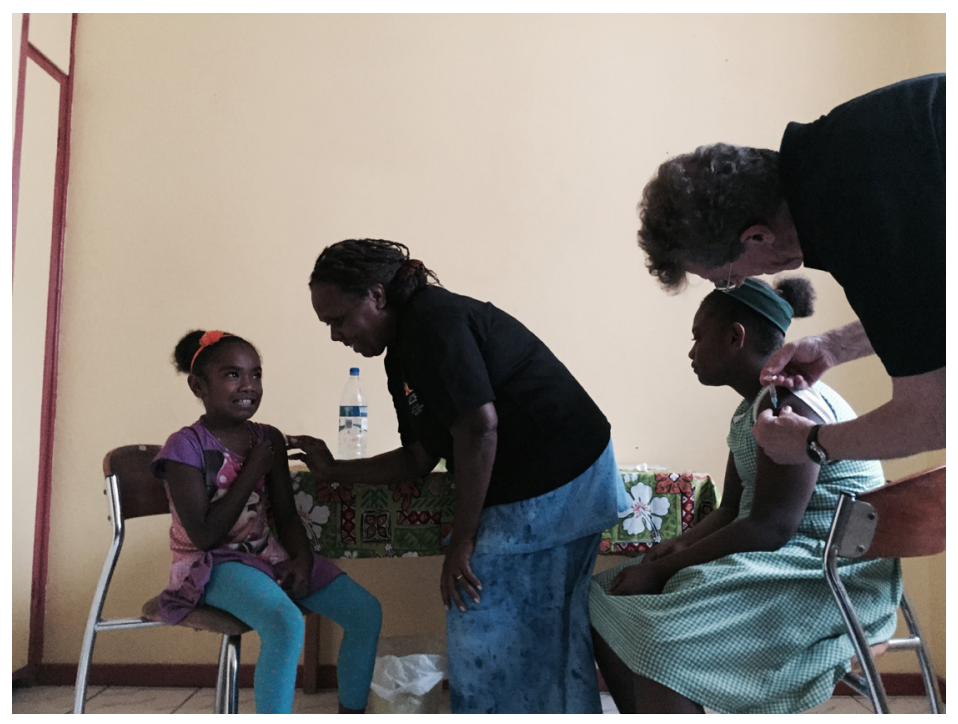

Figure 3 Professor lan Frazer and Ni-Vanuatu nurse Nellie giving the first HPV vaccination at a new Port Villa clinic.

has been the locally driven group IKKANA, a volunteer organization that, since 2017, has organized cervical cancer screening on the islands of Ambrym and Malekula. Furthermore, IKKANA conducts patient education, trains local nurses, and sets up local funds to which women contribute in order to finance travel expenses for patients who need treatment or travel expenses for nurses and doctors to come to the islands to provide consultation locally (Figure 2).

In addition to screening, pilot HPV vaccination studies in Vanuatu achieved

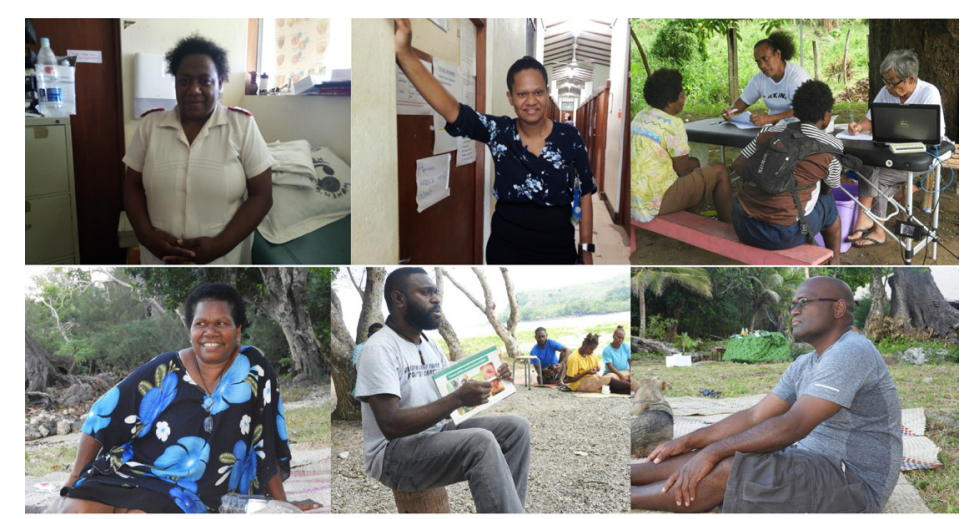

Figure 4 The team in the field. Clockwise from top left: midwife Harriet Obed, Dr Errolyn Tungu, Dephanie Albert and Vera Velanova, Dr Boniface Damutalau, Max Albert (founder of IKKANA), and midwife Charlotte Lingbu. parents must go through a process of 'opting out' if they do not want their child to be immunized rather than needing up-front 'opting in' prior to immunization.

Local and international mobilization and innovation remain necessary to achieve more cervical screening coverage as well as adequate HPV vaccination. Given the enthusiasm and commitment of the Ni-Vanuatu women, nurses, doctors, scientists, volunteers, and donors to achieve so much thus far, we believe that elimination of cervical cancer in Vanuatu is possible (Figure 4).

Correspondence to Dr Emma R Allanson, University of Western Australia, The University of Texas MD Anderson Cancer Center, Houston, TX 77030, USA; emma.allanson@gmail.com

Collaborators Cervical Cancer Foundation (logistics support), Vanuatu Ministry of Health, Sullivan Nicolaides Pathology, Frazer Family Foundation.

coverage in targeted populations of $94 \%$ (5 years of initial HPV vaccinations were donated by the Frazer Family Foundation), and a national HPV vaccination program in Vanuatu is due to come into effect in 2021 (Figure 3). Over the last 5 years many lessons have been learned in delivering cervical cancer prevention programs, one of the most pertinent of which is that HPV vaccinations are more successful when linked with the school tetanus visit program, and when participation in the program is automatic and

Contributors ERA, VV, IHF, and MM all contributed to the design, analysis and the final manuscript.

Funding ERA is funded by a Jean Murray Jones Scholarship from the Royal Australian and New Zealand College of Obstetricians and Gynaecologists.

Competing interests None declared.

Patient consent for publication Not required.

Provenance and peer review Not commissioned; externally peer reviewed.

(c) IGCS and ESGO 2021. No commercial re-use. See rights and permissions. Published by BMJ.

(A) Check for updates

To cite Allanson ER, Velanova V, Frazer IH, et al. Int J Gynecol Cancer 2021;31:631-632.

Accepted 8 October 2020

Published Online First 26 0ctober 2020

Int J Gynecol Cancer 2021;31:631-632. doi:10.1136/ijgc-2020-002129

\section{REFERENCES}

1 The World Bank. Vanuatu, 2020. Available: https://data.worldbank.org/country/vanuatu

2 McAdam M, Sakita J, Tarivonda L, et al. Evaluation of a cervical cancer screening program based on HPV testing and LLETZ excision in a low resource setting. PLOS One 2010;5:e13266.

3 Arbyn M, Weiderpass E, Bruni L, et al. Estimates of incidence and mortality of cervical cancer in 2018: a worldwide analysis. Lancet Glob Health 2020;8:e191-203. 